Article

\title{
Do Smallholder, Mixed Crop-Livestock Livelihoods Encourage Sustainable Agricultural Practices? A Meta-Analysis
}

\author{
Thomas K. Rudel ${ }^{1, *}$, Oh-Jung Kwon ${ }^{2}$, Birthe K. Paul ${ }^{3,+}$, Maryline Boval ${ }^{4,+}$, \\ Idupulapati M. Rao ${ }^{3,+}$, Diana Burbano ${ }^{5,+}$, Megan McGroddy ${ }^{6,+}{ }^{\text {, Amy M. Lerner }}{ }^{7,+}$, \\ Douglas White ${ }^{8, \dagger}$, Mario Cuchillo ${ }^{9,+}$, Manuel Luna ${ }^{10,+}$ and Michael Peters ${ }^{3, \dagger}$ \\ 1 Departments of Human Ecology and Sociology, Rutgers University, 55 Dudley Rd., New Brunswick, \\ NJ 08901, USA \\ 2 The Commission for SSK Multicultural Research, Hanyang University, Seoul 04763, Korea; \\ ziankwon@gmail.com \\ 3 Tropical Forages Program, International Center for Tropical Agriculture (CIAT), Cali, AA 6713, Colombia; \\ b.paul@cgiar.org (B.P.); i.rao@cgiar.org (I.M.R.); m.peters@cgiar.org (M.P.) \\ 4 Livestock Research Program, INRA (L'Institut National de la Recherche Agronomique), Guadeloupe 97170, \\ France; Maryline.Boval@antilles.inra.fr \\ 5 Department of Geography, McGill University, Montreal, QC H3A 0G4, Canada; dianaburbanon@live.com \\ 6 Department of Environmental Sciences, University of Virginia, Charlottesville, VA 22904, USA; \\ mmcgroddy@gmail.com \\ 7 Woodrow Wilson School, Princeton University, Princeton, NJ 08540, USA; amy.m.lerner@gmail.com \\ 8 Research for Development and Conservation, Burlington, VT 05401, USA; dwhite.r4dc@gmail.com \\ 9 Instituto Nacional de Ciencias Medicas y Nutricion, Tlalpan, DF 14080, Mexico; \\ mario.cuchilloh@incmnsz.mx \\ 10 Instituto Nacional de Investigaciones Forestales Agrícolas y Pecuarias, Tecoman 28930, Mexico; \\ silva.manuel@inifap.gob.mx \\ * Correspondence: rudel@aesop.rutgers.edu; Tel.: +1-848-932-9238; Fax: +1-732-932-6667 \\ + These authors contributed equally to this work.
}

Academic Editors: Claudia A. Radel and Jacqueline M. Vadjunec

Received: 15 July 2015; Accepted: 1 February 2016; Published: 6 February 2016

\begin{abstract}
As calls for bolstering ecosystem services from croplands have grown more insistent during the past two decades, the search for ways to foster these agriculture-sustaining services has become more urgent. In this context we examine by means of a meta-analysis the argument, proposed by Robert McC. Netting, that small-scale, mixed crop-livestock farming, a common livelihood among poor rural peoples, leads to environmentally sustainable agricultural practices. As predicted, mixed crop-livestock farms exhibit more sustainable practices, but, contrary to predictions, a small scale of operation does not predict sustainability. Many smallholders on mixed crop-livestock farms use sustainable practices, but other smallholders practice a degrading, input-scarce agriculture. Some large farm operators use soil-conserving, minimum-tillage techniques while other large operators ignore soil-conserving techniques and practice an industrialized, high chemical input agriculture. The strength and pervasiveness of the link in the data between mixed crop-livestock farming and sustainable agricultural practices argues for agricultural policies that promote mixed crop-livestock livelihoods.
\end{abstract}

Keywords: mixed crop-livestock farming; sustainable agriculture; conservation agriculture; smallholders; agro-ecology 


\section{Introduction}

Over the past decade as the intertwined threats of food security, biodiversity losses, and climate change have become more apparent, scientists and policymakers have shown a renewed interest in sustainable agriculture. They have called for the sustainable intensification of agriculture through the adoption of agricultural practices that both increase yields and provide ecosystem services for plants and animals [1]. Practices like mulching, manuring, minimum tillage, and crop rotations foster more biodiverse soils, reduce soil erosion, increase nutrient cycling in soils, and make the food system more resilient in the face of climate shocks [2-4]. The circumstances under which farmers adopt these sustainable practices remain open to question. We address this question through a meta-analysis of data from farms where farmers have or have not adopted sustainable agricultural practices.

More specifically, the meta-analysis assesses the hypothesis that a crop-livestock product mix on small landholdings leads to environmentally sustainable agricultural practices. For this task, we use cases of sustainable and unsustainable agricultural practices which come from published studies of farming in many different geographical locales. We begin by discussing what we mean by "sustainable agriculture." Then we describe a theory about the social and ecological conditions that give rise to sustainable agricultural livelihoods. Under this theory, articulated by Robert McC. Netting, sustainable agriculture emerges most frequently among small-scale farmers who grow crops and raise livestock on the same landholding [5]. An assessment of the potential of mixed crop-livestock farming for fostering sustainable agriculture would test the accuracy of Netting's argument, and also raise questions about the likelihood that mixed crop-livestock farms could become a "seed bed" for the spread of sustainable practices to other farms. This prospect currently seems unlikely because the growing bifurcation in global agriculture between large mechanized operations and very small farms seems to have reduced the numbers of mixed crop-livestock farms. Their decline in numbers would diminish the likelihood that mixed crop-livestock farms could provide the bases for a more sustainable agriculture.

In this uncertain context, we address questions about the contemporary bases for sustainable agriculture. Following a discussion of definitions, we describe Netting's theory about the social and ecological conditions that foster sustainable agricultural practices and present an argument about the ways in which trends in contemporary agriculture may be making sustainable agriculture more difficult to practice. Then we describe our meta-analytic methods and present the findings from the data analyses. The final sections of the paper summarize the socio-ecological conditions that enable sustainable agriculture and identify policy interventions that would expedite its spread.

\section{What is "Sustainable Agriculture"?}

Any effort to analyze sustainable agriculture as a unitary phenomenon has to contend with the variable definitions of the term [6]. It can mean an agriculture that produces enough food for consumers and enough income for farmers. It can also refer to a collection of agricultural practices that maintain agro-ecosystem services like pollination, soil fertility, and pest control on tracts of land at levels sufficient to sustain agricultural activities year after year without heavy doses of chemical inputs. This paper focuses on the determinants of this last, environmental dimension of sustainable agriculture.

Farmers who mulch, minimize tillage, and rotate crops practice "conservation agriculture" (CA) [7]. Sustainable agriculture refers to a wider set of practices. It includes conservation agriculture, but it also includes manuring, because manuring bolsters agro-ecologies (the ecological processes associated with agricultural production systems) by promoting nutrient cycling and building up organic matter in soils [8-10]. A comprehensive index of sustainable agricultural practices would, therefore, have to include manuring as well as rotating crops, leaving crop residues in the fields (mulching), and tilling soils less. The analyses reported below use an index of sustainable agriculture, measured by the presence or absence on farms of these practices, plus an additional presence/absence score for the self-conscious practice of conservation agriculture (CA). This last, rhetorical dimension of the index is meant to capture the discursive element in the practice of sustainable agriculture, which 
in turn may contribute to other farm-specific, and less frequently cited sustainable practices. Box 1 describes the structure of this index more completely.

Box 1. An Index of Sustainable Agricultural Practices.

This index focuses on the most frequently mentioned agricultural practices in discussions of sustainable agriculture. In this respect the index represents a central tendency in sustainable agricultural practices, rather than a comprehensive index which incorporates all possible types of sustainable practices. The index focuses on practices associated with soils and rainfed agriculture. It does not include the extensive conservation measures sometimes found in irrigation systems.

The component practices in the index are as follows:

1. Minimum Tillage (includes no-till, ridge till, and strip till variants). It forestalls soil erosion [7].

2. Mulching with crop residues (includes cover crops and other green manure options). It increases nitrogen in soils and reduces soil erosion [6].

3. Crop rotations (includes strip cropping techniques and other techniques designed to manage pest infestations). It improves control of pests and weeds [6].

4. Manures (deposited by grazing livestock on croplands or by spreading manures from confined livestock on croplands). It increases soil nitrogen availability and therefore soil fertility [10].

5. Professed practitioner of conservation agriculture or organic agriculture (this orientation leads to farm-specific measures, not included above, that would contribute to the environmental sustainability of farm operations).

\section{A Theory: The Ecology of Small-Scale, Sustainable Agriculture}

A broad explanation for the variable adoption of sustainable agricultural practices comes from an agricultural anthropologist. Robert McC. Netting outlined the sources for sustainable agricultural practices among the world's small-scale farmers in Smallholders, Householders: The Ecology of Small Scale, Sustainable Agriculture [5]. Netting drew upon an enormous body of previous work on the economy and ecology of peasant smallholders. He outlined a socio-ecological dynamic in which farmers and other members of their households engaged in laborious routines in which they cultivated an agro-biodiverse set of crops, recycled household, livestock, and agricultural wastes back into production processes, and made a multitude of improvements to their land, like terracing it, irrigating it, and planting fertilizer trees. From Netting's point of view, mixed crop-livestock livelihoods might not be necessary for the practice of sustainable agriculture, but there was a clear affinity between crop-livestock product mixes and sustainable agricultural practices because these practices often entailed the tight integration of animal wastes into crop production processes. For example, almost all of Netting's smallholders used manure from their animals to maintain the fertility of their croplands.

Netting advanced his argument through analyses of similar agro-ecologies in different places, rice cultivators in central China, potato growers in the Swiss Alps, and hill farmers in central Nigeria. A singular pattern runs through agriculture in all of these places. It involves labor intensive activities that, through biological controls and recycling of wastes, refurbish agro-ecologies and promote the long-term sustainability of agriculture. Although Netting does not say so explicitly, his work provides implicit support for the contention that sustainable agriculture is scale dependent, that it occurs most frequently on small farms. In Netting's theory of smallholder agro-ecologies, the different factors are hypothesized to interact in key ways (see Figure 1). The favorable labor to land ratios that frequently prevail on small farms make it possible for households to carry out the labor intensive agricultural tasks, like spreading manure or mulch, that make agriculture sustainable.

Netting's argument had global reach. He saw the theorized dynamic occurring among small farmers in both the Global North and the Global South, among state-supported small farmers in 
Europe as well impoverished rice cultivators in Southeast Asia. In the more than two decades since Netting published his book, a series of scientists, some of them his students [11], have spelled out its implications for environmental change in places where smallholders predominate, further expanding the theory in the process. One field study of smallholders in northern Mexico found that the greater agro-biodiversity associated with smallholder agro-ecologies worked to the benefit of smallholders during times of drought [2]. Other researchers have investigated the association between social capital and smallholder agro-ecology with the idea that social capital might facilitate the creation and maintenance of common property institutions that in turn would maintain a common pool resource like an irrigation system [12]. The emergence of political ecology as a sub-field in Geography and Anthropology has led to a greater appreciation for the political struggles and conflicts that disturb and periodically transform smallholder agro-ecologies [13]. Agricultural scientists have explored similar crop-livestock synergies on somewhat larger farms in the United States [14,15]. Despite all of this work there has never been a quantitative, global-scale assessment of Netting's argument, so the utility of his thesis for understanding global trends in sustainable agriculture remains uncertain.

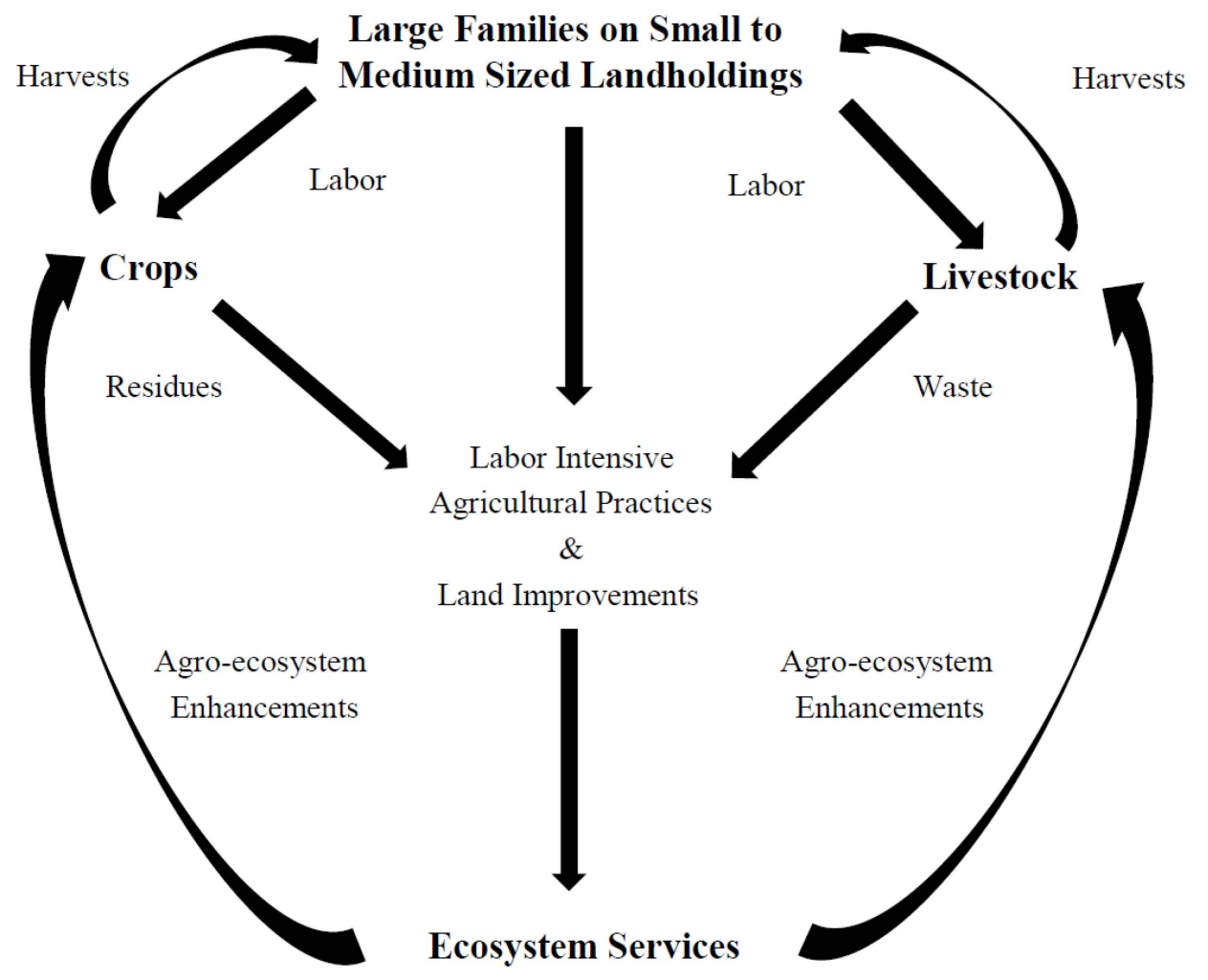

Figure 1. The ecology of small-scale, sustainable agriculture (after Netting, 1993).

\section{A Changing Context: Sustainable Agriculture in a Diverging Agrarian Order}

Two recent trends in agriculture call into question the link between mixed crop-livestock farming and sustainable agricultural practices. First, conservation agriculture (CA), in which farmers pursue environmental sustainability without contributions from livestock, has become more common. Second, small farmers in Sub-Saharan Africa, pressed for additional sources of income, sell crop residues and manure rather than returning these materials to the land. These specific trends derive from a larger, long-established trend towards the bifurcation of the global agricultural sector into large-scale, mechanized farms and small, family-run agricultural plots. This trend may have reduced the proportion of landholdings where people might be able to practice the mixed crop-livestock agro-ecology described by Netting. This diverging dynamic is described below, beginning with the continuing growth in the numbers of large-scale farms. 
While large-scale plantations in coastal locations in the tropics and sub-tropics date from the 17th century [16], the trend in the United States' Middle West and Plains states towards larger farms dates from the early 20th century when homesteading ended. Farmers have specialized, as their farms have gotten larger, with the larger farms focused increasingly on only cultivating crops [17]. The segregation of crops from animals eliminated the synergies between crop cultivation and animal waste that had characterized so much sustainable agriculture. Farmers benefited from the segregation of crops from animals on large farms because they could obtain economies of scale in the purchase of larger quantities of the smaller range of inputs needed to grow crops. The per-unit costs of inputs like fertilizer declined for these farmers, even as the total amount of their expenditures on inputs climbed with the increase in the scale of their farms. The decline in per unit input costs proved very important to farmers during the 1920 to 2005 period when the price of agricultural products rose more slowly than manufactured goods. For many family farmers it was get big or get out [17]. All of these operations became more specialized and more mechanized as they got larger, so the large operators spent more money on a few specialized inputs, like machinery. In this context some innovations central to CA, like reduced tillage, grew more attractive to large operators because they promised to reduce further the costs of inputs of machinery, fuel, and labor [7].

This dynamic changed during the 2008 economic crisis when some rice-producing countries suddenly banned the export of rice [18]. Driven by concerns about food security or by desires to profit from food security concerns, groups of private investors began to engage in "land grabs," in which they acquired large tracts of land which they then dedicated to the production of foodstuffs for markets overseas [19]. The expansion in the scale of agricultural operations continued, but new groups of operators became the owners of agricultural lands.

CA typically has three components, minimum tillage, mulching of agricultural residues, and the planting of nitrogen-fixing cover crops when croplands are not being cultivated [20]. These agricultural practices were first widely adopted during the Dust Bowl era [21], but they only became recognized as a package of sustainable practices when farmers began to talk about them and adopt them on fairly large, erosion prone, crop-only farms in Kentucky during the 1960s [7]. Governments have generally not provided incentives for $\mathrm{CA}$, but it has appealed to farmers because, in the places where it can be practiced, CA limits the numbers of times that farmers have to turn the earth, and this reduction in ploughing reduces the costs of labor and gasoline to run agricultural machinery [6,7]. Because CA adopters have typically had large areas of cropland, they have had the economic capital to invest in minimum tillage machinery and in herbicides to prevent weed infestations. The CA regimen also boosts nutrient recycling in croplands because the organic waste in crop residues and cover crops recycles nitrogen back into the soils [6]. CA does not, however, conform to the smallholder agro-ecology outlined by Netting because it does not typically mix livestock with the cultivation of crops.

Foundations and development assistance agencies have recently tried to promote the adoption of CA practices among smallholders in Sub-Saharan Africa. The CA regimen does conserve soil moisture and thereby benefits plants in zones with erratic rainfall, but, aside from this advantage, CA has failed to produce yield gains consistently in Sub-Saharan Africa, which in turn has limited its appeal [22,23]. CA has been most widely adopted in countries like Canada with agricultural sectors in which large farms predominate [20].

While on a global scale some farms were expanding in size during the 20th century, other farms, particularly in South Asia and some regions of Sub-Saharan Africa, were declining in size. Large numbers of smallholders in South Asia and Sub-Saharan Africa have become proletarianized as a byproduct of a continuing subdivision of smallholdings through inheritance [24]. These smallholders began to work at least part-time as farm laborers because they could no longer earn a sufficient income from the small plot of land that they owned. In these circumstances landholdings in densely populated districts of, for example, western Kenya became so small (less than 0.4 hectares) that the owners had to maximize their revenue from the land, however they could, in order to survive. To generate 
income, they sold the crop residues and the manure from confined livestock rather than returning the manure to the land, so over time the soils on their landholdings degraded [24]. They were caught up in a natural resource degrading poverty trap [25].

A more socially benign version of this dynamic might apply to small farms in peri-urban districts where non-farm employment has reduced the family labor force to the point where no one has the time to perform the time-consuming, land-improving tasks of, for example, spreading manure. These dynamics involving the smallest landholdings, like those involving CA on the largest landholdings, depart from the theory of smallholder agro-ecology because they sever the connection between livestock and the land. They suggest that the bifurcation of global agriculture into large and very small farms has reduced the numbers of farms on which smallholder, mixed crop-livestock agro-ecology would be feasible. The meta-analysis presented below assesses this conjecture. It analyses the prevalence of sustainable agricultural practices across different types and sizes of farms, including some with crop-livestock mixes.

\section{Methods and Materials}

\subsection{Case Selection and Farmer Categorization}

To answer questions about the social and ecological conditions that foster sustainable agriculture, we reviewed and collected all of those studies that asked farmers about agricultural practices on their farms. The data in these studies make it possible to investigate the patterns of association between the characteristics of farms and sustainable agricultural practices. From this large set of studies, we selected for the meta-analysis those studies in which we could identify sets of farmers that practiced or did not practice sustainable agriculture. The authors of these studies created typologies of farmers, based on the size of their operations, the presence or absence of a crop-livestock product mix, and the prevalence of sustainable agricultural practices.

We wanted to identify the attributes of farms that had an effect on the probability that farmers would cultivate their lands in environmentally sustainable ways. Measurement problems precluded the measurement of the magnitude of these effects beyond the binary of statistically significant or insignificant. We just wanted to find out if a particular variable, the size of a farm or the presence of a mixed livestock-crop operation, made it significantly more likely that a farmer would employ practices that contribute to the environmental sustainability of agriculture on his/her farm. To answer this question, we looked for patterns across the case studies of farming in different geographical locales.

To assemble an exhaustive list of articles on types of farms and sustainable agricultural practices, we searched the scientific literature in the four different languages that we were able to read (English, French, Spanish, and Portuguese). We used one search engine (Google), the Web of Science database, and the International Livestock Research Institute's database. We employed a range of search terms including "agro-pastoral" and "crop-livestock." Personal knowledge of the relevant literatures also helped us to identify some case studies. These searches produced a list of 148 studies for possible inclusion in the meta-analysis. We examined all of these articles and, using the criteria outlined below, we ended up with 39 studies, including several books as well as articles. The 39 studies identified 141 types of farmers, some of whom practiced sustainable agriculture and some of whom did not. All of the case studies that we identified had publication dates after 1980.

To reduce the likelihood of selection bias in choosing case studies for analysis [26], we sampled on the independent variable of greatest interest, the presence or absence of a mixed crop-livestock operation on a farm. We searched for studies that reported variations from farm to farm in product mixes (crop-livestock, crop-only, livestock-only) and in sustainable agricultural practices like manuring, tillage frequency, crop rotations, and mulching (see Box 1). Using these criteria, we eliminated many studies from consideration. For example, some studies could not be included in the database because they presented models of sustainable and conventional farms instead of data on actual agricultural practices. Similarly, studies of conventional and alternative agricultural practices in experiment station 
settings did not represent the practices of actual farm households, so they could not be included in the study. Although a particular survey of farmers may have served as the basis for multiple publications, it only appears once in the database to prevent the double counting of data from particular farms.

The 141 different types of farmers in the 39 studies represent aggregated data from 6253 farms. The 39 studies are listed in the Supplementary Materials for this article. The immediate contexts of the studies varied tremendously. For example, a study of farmers in eastern Bolivia compared the agricultural practices of cattle ranchers (one type of farmer) with the practices of crop-livestock farmers (another type of farmer). Researchers in Kenya compared the agricultural practices of dairy farmers with crops and several cows (one type of farmer) with the agricultural practices of farmers who only grew corn (another type of farmer). In a study in the United States, researchers compared the agricultural practices of grain-only farmers (one type of farmer) with the agricultural practices of other farmers who grew grain and maintained livestock on their land (another type of farmer).

Given that researchers frequently selected the sites for case studies for idiosyncratic reasons, the cases in this meta-analysis cannot properly be considered to be anything other than a non-random sample from the universe of agricultural regions. The assembled case studies can, however, be evaluated in the same way that we would assess a purposive sample. It would be considered adequate for our analytic task if the 39 studies contained a sufficient range of variation from case to case to address the substantive hypothesis under consideration. There would have to be variations from farm type to farm type in sustainable agricultural practices and in crop-livestock, crop-only, and livestock-only product mixes. The 141 farm types contain variation along these dimensions. The numbers of farm types in different categories are listed below in parentheses. The assembled studies have crop-livestock types of operations (111) and more specialized crop-only or livestock-only farm types (30). The studies span the developed (44 farm types) and the developing world (97 farm types) with cases from North America (23), Latin America (15), Europe (17), Asia (19), Oceania (4), and Sub-Saharan Africa (63). The size of farms for each farm type was also reported. These variations in the data make it possible to assess the link between mixed crop-livestock operations and sustainable agricultural practices across a broad range of places.

Each of the 39 studies was read by multiple people, and the inevitable disagreements about how to code a particular case were resolved in discussions among the team of readers. Practices were coded as 'present' or 'absent' based on quantitative and qualitative data presented in the original article. In addition to the coded practices from the farms in each case study, the database contains data about the agricultural contexts of the case studies, in particular about the agricultural policies of the countries in which researchers did the case studies.

\subsection{Quantitative Analyses}

For our quantitative analyses, we built generalized linear models (GLM) of variations from farm type to farm type in sustainable agricultural practices. For these multivariate analyses, we supplemented data from the case studies with data from other sources (see Table 1). For our dependent variable, we employed an index that sums four common agricultural practices (minimum tillage, crop rotation, mulching crop residues, and manuring) that conserve soils and soil nutrients. To this sum, we added an additional variable that indicates whether or not the farmer knowingly practices sustainable agriculture or CA. When a series of items represent different, but still substantively related behaviors and their values co-vary from case to case, they represent a scale of a particular phenomenon, in this case the sustainability of agricultural practices. Testing for the appropriateness of treating these five items as a scale resulted in an acceptable Cronbach's alpha (a measure of how much items in a scale vary together) of 0.617 . The relatively low alpha may reflect the differences in the substance of sustainability practices from the large-scale practitioners of CA to the smallholders who practice mixed crop-livestock agriculture.

Generalized linear models (GLM) are the preferable models for multivariate analyses when the dependent variable has a non-normal distribution, which is the case with an ordinal variable like our 
scale of sustainable agriculture. In addition it seemed heuristically useful to carry out, in addition to the global-scale GLM analysis, separate analyses of studies from the developed and developing worlds because the largest farms were in the developed countries and the smallest farms were in the developing world (see Table 2). There were influential cases in the developed and developing countries analyses - two cases in the developed country analysis and one case in the developing country analysis. These cases were removed. Their removal from the analyses did not, however, produce any substantively meaningful changes in the GLM coefficients for the predictor variables. This diagnostic test indicates a relatively robust set of findings from the multivariate analyses.

Table 1. Definitions and sources for variables in the multivariate analyses.

\begin{tabular}{|c|c|c|}
\hline Variables & Values & Sources \\
\hline \multicolumn{3}{|l|}{ Dependent Variable } \\
\hline $\begin{array}{l}\text { Sustainable Agriculture Index: Presence }(1) \text { or } \\
\text { absence }(0) \text { of manure on fields }+ \text { reduced tillage }+ \\
\text { crop rotation }+ \text { mulching of stubble and litter }+ \\
\text { conscious practice of conservation or sustainable } \\
\text { agriculture. }\end{array}$ & $0-5$ & Case studies \\
\hline \multicolumn{3}{|l|}{ Independent Variables } \\
\hline Mixed Crop-Livestock Agriculture & $0=$ No, $1=$ Yes & Case studies \\
\hline Tree Crops on Farms & $0=$ No, $1=$ Yes & Case studies \\
\hline Farm Labor & $\begin{array}{c}0=\text { Some or all hired labor } \\
1=\text { Family labor }\end{array}$ & Case studies \\
\hline Government Subsidies for Agricultural Products * & $\begin{array}{l}\% \text { of the value of agricultural } \\
\text { products in the country containing } \\
\text { the case study site. }\end{array}$ & [27] \\
\hline
\end{tabular}

* The subsidies vary in form from country to country. In some countries, like the United States, the government subsidizes the production of a crop like corn. In other countries, like Cameroon, the government subsidizes the acquisition of inputs like fertilizer for crops like cacao. Whatever the form of the subsidy, it can be converted into a proportion of the market value of the crop.

Table 2. Farm characteristics and conservation practices: developed and developing countries.

\begin{tabular}{|c|c|c|c|c|c|c|c|c|c|}
\hline & \multicolumn{3}{|c|}{ Farm Characteristics } & \multicolumn{6}{|c|}{ Conservation Practices (\% of Farms) } \\
\hline $\begin{array}{c}\text { Developed } \\
\text { Countries } \\
\text { (Europe, N. } \\
\text { America, } \\
\text { Oceania) }\end{array}$ & $464^{* * *}$ & $55^{* * *}$ & $1.98^{* * *}$ & $66^{*}$ & $41^{* * *}$ & $63^{*}$ & 54 & $10^{* * *}$ & 2.57 \\
\hline $\begin{array}{l}\text { Developing } \\
\text { Countries } \\
\text { (Africa, Asia, } \\
\text { Latin America) }\end{array}$ & 31 & 89 & 2.51 & 79 & 9 & 76 & 45 & 40 & 2.21 \\
\hline
\end{tabular}

Notes: Significance of Difference of Means: ${ }^{* * *}<0.001,{ }^{* *}<0.01,{ }^{*}<0.10$. The number of agricultural products is an ordinal level variable with three categories ranging from 1 to $3: 1=1$ or 2 crops, $2=3$ or 4 crops, $3=5+$ crops. Crop-livestock farms, manuring, less tillage, crop rotation, stubble mulching, little-no chemical fertilizer are all binary variables $(1=$ yes, $0=$ no). The percentages refer to the percentage of farm types from these countries that exhibit the characteristic or engage in the particular conservation practice.

\section{Results}

We identified several important aggregate differences between richer and poorer countries in their farms and in their sustainable agriculture practices (see Table 2). The farms from the wealthier nations tended to be larger and specialized in either crops or livestock. Farmers from developed countries relied heavily on external (chemical) inputs. Among the sustainable agricultural practices, 
they emphasized minimum tillage. Farmers from the poorer countries had less land. They operated more mixed crop-livestock farms and produced a greater diversity of agricultural products than did farmers in the wealthier countries. Farmers in the developing world were more likely to choose, among the sustainable practices, to spread manure on their fields, rotate crops, and intercrop them.

The GLM analyses (Table 3) suggest explanations that would account for the differences between farm types in the frequency with which they practice sustainable agriculture. The most striking finding concerns the strong association between mixed crop-livestock operations and sustainable practices. It is the strongest effect in the global, developed, and developing country analyses. Farm size did not predict sustainable practices in any of the analyses, so it is not included among the independent variables in Table 3. There are also some substantive differences between the three analyses. In the global-scale analysis (column 1 of Table 3 ) the size of agricultural subsidies associates positively with sustainable practices. This effect, although weaker than the mixed crop-livestock effect, underscores how in the wealthier countries the subsidies, which encourage an expansion in the size of farms, are compatible with some sustainable agricultural practices like minimum tillage and stubble mulching. In the developed country equation (column 2), mixed crop-livestock operations associate positively with sustainable practices, as does family farming (where all of the labor comes from the family). For the farms in the developed countries, those that relied exclusively on family labor, while large in an international context (mean $=326$ hectares), were smaller than farms that hired labor (mean $=624$ hectares) and were more likely to use crop residues as mulch in their fields. In the developing country subsample (column 3 in Table 3), mixed crop-livestock operations made more use of sustainable practices, as did farms that harvested tree crops along with other agricultural products. The salience of tree crops reflects the widespread planting of fertilizer, fruit, and fodder trees on smallholdings, particularly in Sub-Saharan Africa and Central America.

Table 3. Variations in sustainable agriculture practices across farm types: B coefficients from generalized linear models ${ }^{\dagger}$.

\begin{tabular}{cccc}
\hline & $\begin{array}{c}\text { (1) All Cases: } \\
\text { Global Pattern }\end{array}$ & $\begin{array}{c}\text { (2) Cases from } \\
\text { Developed Countries }\end{array}$ & $\begin{array}{c}\text { (3) Cases from } \\
\text { Developing Countries }\end{array}$ \\
\hline Mixed Crop-Livestock Farms & $-1.577^{* * *}(0.282)$ & $-1.815^{* * *}(0.521)$ & $-1.376^{* * *}(0.319)$ \\
Tree Crops on Farms & $-0.627^{*}(0.260)$ & & $-0.657^{* *}(0.229)$ \\
Government Subsidies for Agriculture & $0.076^{* *}(0.018)$ & $-0.037(0.079)$ & $-0.037(0.091)$ \\
Labor Source (Family =1) & $-0.127(0.205)$ & $-0.956^{*}(0.513)$ & $0.155(0.205)$ \\
Farm Size & $0.019(0.028)$ & $-0.035(0.057)$ & $0.023(0.081)$ \\
Likelihood Ratio & 39.05 & 13.10 & 30.20 \\
Chi Square & $($ sig. 0.000$)$ & $($ sig. 0.011$)$ & $($ sig. 0.000$)$ \\
N of Cases & 133 & 36 & 97 \\
\hline
\end{tabular}

Notes: ${ }^{* * *}<0.001,{ }^{* *}<0.01,{ }^{*}<0.10 .{ }^{\dagger}$ The equations for the different geographic groupings of farms describe the efficacy of different factors, analyzed together, in predicting the score of a particular farm type on the index of sustainable agricultural practices. The B coefficients (unstandardized regression coefficients) indicate the change in the response variable when the predictor variable is set to 0 (not present in the case of the mixed crop-livestock and tree crop variables). The numbers in parentheses are the standard errors of the Bs. There were no cases of farm types with tree crops in the developed country subsample. Given the use of the maximum likelihood estimation framework, the significance tests for the partial regression coefficients are for Wald Chi Squares. Missing data for the labor variable, along with the removal of the three influential cases, reduced the number of cases in the analysis to 133.

\section{Discussion}

The importance of mixed crop-livestock operations for the practice of sustainable agriculture is the clearest finding to emerge from the meta-analysis. The presence of animals on farms where people also cultivate crops encourages cultivators to recycle animal wastes onto croplands, and these practices seem to encourage farmers to adopt other practices like the rotation of cover crops and minimum tillage that also enhance agricultural sustainability. This tight integration of the recycling of animal wastes with crop production is the hallmark of the sustainable production practices in Netting's [5] theory 
about the ecology of small-scale, sustainable agricultural livelihoods. For this reason the association of mixed crop-livestock farming with sustainable agricultural practices in the meta-analysis provides broad confirmation for Netting's approach to understanding the sources for sustainable agriculture.

This finding takes on added significance given the projections of more variable and more extreme climatic conditions in the future. An acceleration in climate change would probably reinforce the attractiveness of mixed crop-livestock practices to farmers, largely because the greater diversification of these mixed operations might reduce the risk of complete crop failures when climatic conditions fluctuate [2]. For example, adverse climactic conditions for a row crop might not limit animal production on a farm. The same logic of diversification in the face of climate change would appear to favor the spread of tree crops on farms with row crops. Because the greater agro-biodiversity of mixed farming would presumably enable mixed-crop livestock farmers to survive climatic extremes more easily, they should exhibit more resilience during periods of recovery [6]. The superiority of the sustainable practices used by mixed crop-livestock farmers may however depend on the types of extreme weather encountered. A recent global meta-analysis of differences in crop yields between conventional and conservation agriculture concluded that the practice of conservation agriculture led to yield losses in humid growing conditions and to yield gains in arid conditions, presumably because CA practices increased moisture retention in soils during droughts [28].

Other findings from the meta-analysis point indirectly to the social and ecological limits of Netting's theory. The argument that small farmers practice more sustainable agriculture does not receive support. The ongoing divergence in the agrarian sector, outlined above, may explain the absence of a relationship between farm size and sustainable agricultural practices across the studies. First, the spread of conservation agriculture (CA) across the agricultural sectors of the grain-exporting nations has made sustainable practices more common among large growers [6,20], but, because it does not mix crops with livestock and does not involve manuring, CA represents a somewhat different form of sustainability than the smallholder agro-ecologies described by Netting. Second, changes at the other end of the size distribution of farms have weakened the association between smallholdings and sustainability. In densely settled, impoverished districts of South Asia and Sub-Saharan Africa, the number of agriculturally unsustainable smallholdings appears to be increasing [24].

In sum it would seem that the growing worldwide bifurcation in agricultural livelihoods between large, highly capitalized agricultural operations and poorly capitalized smallholdings has begun to characterize sustainable agricultural practices as well. Conservation agriculture (CA), with its less invasive treatments of soils and redesigned machinery represents ecological modernization [29], a process of change that depends on technological innovations and characterizes large-scale, highly capitalized agricultural economies. The natural resource degrading poverty traps afflicting the poorest landowners represent substantively a type of proletarianization in which smallholders are over time reduced to selling their own labor as the productive value of their land falls to zero. The dynamics that characterize both of these processes depart dramatically from the smallholder agro-ecologies described by Netting. The increasing numbers of these very large and very small farms suggest that the mixed crop-livestock agro-ecologies found on small to middle sized farms may be declining in number.

\section{Conclusion: Limitations and Implications for Policy}

The limits of the analysis presented here temper our conclusions in important ways. First, we have focused only on the environmental sustainability of agricultural practices, so important factors in the overall acceptance of these practices by cultivators, in particular their economic return, have not been systematically considered here. Second, there are shifting cultivators, probably declining in number, whose practices are not fairly represented in any of the case studies, so generalizations about synergies between crops and livestock in their livelihoods are beyond the scope of this analysis [30]. Similarly, the sample does not contain a large enough number of cases of some agro-ecological practices like silvo-pastoralism and establishment of pollination corridors to warrant generalizations about the 
determinants of these practices. With these caveats in mind, we explore the policy implications of the preceding analysis.

Two conclusions with policy implications would seem to follow from the foregoing analysis. First, as emphasized elsewhere [6], the substance of sustainable agricultural practices appears to vary with the size of farms. Larger farms seem more frequently to specialize their operations, focusing in particular on crop-only operations. For these farms the path towards more environmentally sustainable operations may involve the introduction of new machines and new seeds that increase the ecosystem services and economic returns associated with conservation agriculture. For the usually, but not invariably, middle-sized farms with product mixes that include livestock as well as crops, innovations in sustainability would try to capitalize on the synergies present at the interface between crops and livestock on farms. These innovations might apply on even the smallest crop-livestock operations in poor districts of the rural South. In sum, policymakers would want to encourage environmentally sustainable agriculture in different ways depending on the size of the participating farmers' landholdings [31].

A second, more structural policy implication acknowledges and tries to build upon the primary finding from this analysis, the strong relationship between mixed crop-livestock operations and agricultural practices that promote environmental sustainability. Given the historical role that increases in the size of agricultural operations played in the segregation of crop from livestock production and the loss of environmental synergies that has come with the disappearance of crop-livestock operations, land reforms [32] that reduce the size of the larger operations might provide some environmental synergies by making the more diverse, climate resilient crop-livestock operations more appealing to farmers who, after the reform, would cultivate middle-sized farms. The appeal of mixed crop-livestock operations grows when the land base for farms is limited because crops plus livestock generate multiple streams of income from fairly small tracts of land. Compared to larger farms, a higher proportion of the total land area on these middle-sized farms would be under cultivation, so farmers might bring sub-marginal lands into cultivation after a land reform, as they did in Bolivia in the 1950s [33]. In sum, there would be environmental trade-offs with a land reform, increases in sustainable procedures on fields occupied by livestock at the cost of increases in the cultivation of sub-marginal lands. These structural reforms will most likely only work if they are accompanied by familiar government and NGO initiatives like lines of credit for innovations in sustainable agriculture and certification schemes that promise higher returns for growers who produce crops in sustainable ways.

Supplementary Materials: The following are available online at www.mdpi.com/2073-445X/5/1/6/s1, Supplementary Materials: Case Studies Included in the Meta-analysis.

Acknowledgments: Holly Berman provided valuable assistance in the conduct of this research. Funds from National Science Foundation Grant CNH10009499 facilitated this research. Researchers from CIAT received funds from two CGIAR Research Programs: (1) Livestock and Fish, and (2) Climate Change, Agriculture, and Food Security (CCAFS).

Author Contributions: TKR and OJK engaged in case selection, coding, and data analysis. The other authors made contributions to the search for relevant case studies.

Conflicts of Interest: The authors declare no conflict of interest.

\section{References}

1. Montpellier Panel. Sustainable Intensification: A New Paradigm for African Agriculture; Agriculture for Impact: London, UK, 2013.

2. Eakin, H. Weathering Risk in Rural Mexico: Climatic, Economic and Institutional Change; University of Arizona Press: Tucson, AZ, USA, 2006.

3. Intergovernmental Panel on Climate Change (IPCC). Climate Change 2014: Mitigation of Climate Change; Cambridge University Press: Cambridge, UK, 2014.

4. Palm, C.; Blanco-Canqui, H.; DeClerck, F.; Gatere, L.; Grace, P. Conservation agriculture and ecosystem services: An overview. Agric. Ecosyst. Environ. 2014, 187, 87-105. [CrossRef] 
5. Netting, R.M. Smallholders, Householders: The Ecology of Small Scale, Sustainable Agriculture; Stanford University Press: Stanford, CA, USA, 1993.

6. National Research Council. Towards a Sustainable Agriculture for the 21st Century; National Academies Press: Washington, DC, USA, 2010.

7. Coughenour, C.M.; Chamala, S. Conservation Tillage and Cropping Innovation. Constructing the New Culture of Agriculture; Iowa State University Press: Ames, IA, USA, 2000.

8. Edmeades, D.C. The long-term effects of manures and fertilizers on soil productivity and quality: A review. Nutr. Cycl. Agroecosyst. 2003, 66, 165-180. [CrossRef]

9. Rusinamhodzi, L.; Corbeels, M.; Zingore, S.; Nyamangara, J.; Giller, K. Pushing the envelope? Maize production intensification and the role of cattle manure in recovery of degraded soils in smallholder farming areas of Zimbabwe. Field Crop. Res. 2013, 147, 40-53. [CrossRef]

10. Sommerfeldt, T.G.; Chang, C; Entz, T. Long-term annual manure applications increase soil organic matter and nitrogen and decrease the carbon to nitrogen ratio. Soil Sci. Soc. Am. J. 1988, 52, 1668-1672. [CrossRef]

11. Wilk, R.R.; Stone, P. Introduction to a very human ecology: Celebrating the work of Robert McC. Netting. Hum. Ecol. 1998, 26, 175-188. [CrossRef]

12. Ostrom, E. Crossing the great divide: Coproduction, synergy, and development. World Dev. 1996, 24, 1073-1086. [CrossRef]

13. Peters, P. Inequality and conflict over land in Africa. J. Agrar. Change 2004, 4, 269-314. [CrossRef]

14. Sulc, R.M.; Tracy, B.F. Integrated crop-livestock systems in the US Corn Belt. Agron. J. 2007, 99, 335-345. [CrossRef]

15. Hendrickson, J.; Sassenrath, G.; Archer, D.; Hansen, J.; Halloran, J. Interactions in integrated U.S. agricultural systems: The past, the present, and the future. Renew. Agric. Food Syst. 2008, 23, 314-324. [CrossRef]

16. Mintz, S. Sweetness and Power: The Place of Sugar in Modern History; Viking: New York, NY, USA, 1986.

17. Hart, J.F. The Changing Scale of American Agriculture; University of Virginia Press: Charlottesville, VA, USA, 2004.

18. Sharma, R. Food Export Restrictions: Review of the 2007-2010 Experience and Considerations for Disciplining Restrictive Measures; FAO Commodity and Trade Policy Research Working Paper, No. 32; Food and Agricultural Organization of the United Nations: Rome, Italy, 2011.

19. Borras, S.; Hall, R.; Scoones, I.; White, B.; Wolford, W. Towards a better understanding of global land grabbing: An editorial introduction. J. Peasant Stud. 2011, 38, 209-216. [CrossRef]

20. Hobbs, P.R. Conservation agriculture: What is it and why is it important for future sustainable food production. J. Agric. Sci. 2007, 145, 127-137. [CrossRef]

21. Hurt, R.D. The Dust Bowl: A Cultural and Social History; Nelson-Hall: Chicago, IL, USA, 1981.

22. Giller, K.; Witter, E.; Corbeels, M.; Tittonell, P. Conservation agriculture and smallholder agriculture in Africa: The Heretics view. Field Crops Res. 2009, 114, 23-34. [CrossRef]

23. Corbeels, M.; de Graaff, J.; Nash, T.; Penot, E.; Baudron, F.; Naudin, K.; Andrieu, N.; Chirot, G.; Schuler, J.; Nyagumbo, I.; et al. Understanding the impact and adoption of conservation agriculture in Africa: A multi-scale analysis. Agric. Ecosyst. Environ. 2014, 187, 155-170. [CrossRef]

24. Valbuena, D.; Erenstein, O.; Tui, S.H.-K.; Abdoulaye, T.; Claessens, L.; Duncan, A.; Gerard, B.; Rufino, M.C.; Teufel, N.; van Rooyen, A.; et al. Scoping crop residue trade-offs in Sub-Saharan Africa and South Asia. Field Crops Res. 2012, 132, 175-184. [CrossRef]

25. McPeak, J.; Barrett, C. Differential risk exposure and stochastic poverty traps among East African pastoralists. Am. J. Agric. Econ. 2001, 83, 674-679. [CrossRef]

26. Berk, R.A. An introduction to sample selection bias in sociological data. Am. Sociol. Rev. 1983, 48, 386-398. [CrossRef]

27. Anderson, K.; Martin, W.; Valenzuela, E. The relative importance of global agricultural subsidies and market access. World Trade Rev. 2006, 5, 357-376. [CrossRef]

28. Pittelkow, C.; Liang, X.; Linquist, B.; van Groenigen, K.; Lee, J.; Lundy, M.; van Gestel, N.; Six, J.; Venterea, R.; van Kessel, C. Productivity limits and potentials of the principles of conservation agriculture. Nature 2015, 517, 365-368. [CrossRef] [PubMed]

29. Mol, A.J.; Sonnenfeld, D. Ecological Modernization around the World: Perspectives and Critical Debates; Frank Cass: London, UK, 2000. 
30. Van Vliet, N.; Mertz, O.; Heinimann, A.; Langanke, T.; Pascual, U.; Schmook, B.; Adams, C.; Schmidt-Vogt, D.; Messerli, P.; Leisz, S.; et al. Trends, drivers and impacts of changes in swidden cultivation in tropical forest-agriculture frontiers: A global assessment. Glob. Environ. Change 2012, 22, 418-429. [CrossRef]

31. Hayami, Y.; Ruttan, V. Agricultural Development: An International Perspective; Johns Hopkins University Press: Baltimore, MD, USA, 1971.

32. Lipton, M. Land Reform in Developing Countries: Property Rights and Property Wrongs; Routledge: London, UK, 2009.

33. Preston, D. The revolutionary landscape of highland Bolivia. Geogr. J. 1969, 135, 1-17. [CrossRef]

(C) 2016 by the authors; licensee MDPI, Basel, Switzerland. This article is an open access article distributed under the terms and conditions of the Creative Commons by Attribution (CC-BY) license (http://creativecommons.org/licenses/by/4.0/). 